\title{
A COMPILATION RESEARCH OF ERP IMPLEMENTATION CRITICAL SUCCESS FACTORS
}

\author{
Zhenyu Huang, Central Michigan University, huang1z@cmich.edu
}

\begin{abstract}
This article is a review of work published in various journals and special conferences on topic of Critical Success Factors (CSF) of Enterprise Resource Planning (ERP) system implementation between 1998 and 2007. A total of 524 articles were reviewed, which includes 32 CSF literatures. This paper intends to serve three goals. First, it will be useful to researchers who are interested in studying ERP CSF field. Second, it will be a useful resource to find ERP CSF research topics. Third, it will serve as a comprehensive bibliography of the ERP CSF articles published during this 10 year period. The literature was analyzed under 2 categories and 2 time periods.
\end{abstract}

\section{INTRODUCTION}

Since the 1990's, there is an increasing demand in Enterprise Resource Planning (ERP) Systems in organization to keep competitive(Holland \& Light, 1999). Until now, ERP systems are still a very hot issue in both the academic and business world. According to recent AMR research (2007), ERP vendor revenue across all segments is expected to grow from $\$ 28.8$ billion in 2006 to $\$ 47.7$ billion by 2011. However, some published reports and papers (Ribbers \& Schoo, 2002; Shanks et al., 2000; Willis \& Willis-Brown, 2002) still indicate that the successful implementation of ERP continues to be challenging for organizations. A survey of ERP project managers (Peterson, Gelman, \& Cooke, 2001) found that $40 \%$ of respondents failed to achieve their original business case even after being live for a year or more; meanwhile, more than $20 \%$ of managers stated that they actually shut down their projects before completion. From the later 90's to the present, there are a lot of papers focusing on critical success factors (CSFs) of ERP implementation. It is time for us to re-examine these CSFs and develop an updated list that really helps successful ERP implementation in business organizations. Based on a comprehensive analysis of ERP implementation success factors, this paper is a review of the literature on ERP CSF articles published between 1998 and 2007 (31 Nov).

This paper intends to serve three goals. First, it will be useful to researchers who are interested in studying ERP CSF field. Second, it will be a useful resource to find ERP CSF research topics. Third, it will serve as a comprehensive bibliography of the ERP CSF articles published during this 10 year period.

\section{LITERATURE REVIEW}

Among the identified articles, the early published study on CSFs in Manufacturing Resource Planning (MRPII) implementation was by Duchessi et al. (1988). The CSFs suggested in the article are: project champion; project management; business plan and vision; top management support; effective communication and change management program and culture. Because ERP and MRP are both sophisticated and based on the central information systems for the enterprise, the CSFs of the MRP and MRPII implementations are relevant to ERP implementation, also their implementation require similar resources (Loh \& Koh, 2004).

Bingi et al. (1999) suggested that critical factors affecting ERP implementation are top management commitment; reengineering; integration; ERP consultants; implementation time; implementation cost; ERP vendors; as well as selecting the right employees; employee training; and employee morale. However, Ehie et al. (2005) emphasized on performance measure; smaller scope; cooperation 
between enterprise and vendor; open and honest communication and knowledge management.

Extensive research also showed that people are a major factor in detecting the performance of an ERP implementation in an enterprise. Turnipseed $e t$ al. (1992) found that people's involvement in implementation, support for the system and the level of usage are highly correlated to the success of such a system. However, it was found that prior experience with complex information systems and the level of education and training are not important factors in perceptions of the success of this system. In contrast, Mainwaring (1999) argued that users' training is the key to ERP implementation. Gefen also suggested that nurturing clients' trust to encourage a successful customization is a key factor for a successful ERP implementation (2002).

\section{METHODOLOGY}

Papers published in the journal and special conferences between 1998 and 2007 were chosen, which involves extensive note taking that has highlighted any possible condition to CSFs. To compare these papers, those which are concentrated on ERP topic published during the same 10 year period were picked. The data collection phase of the literature review has involved an exhaustive search of many of the prominent MIS journals including, but not limited to, those outlined below:

- Business Process Management Journal

- European Journal of Information Systems

- Americas Conference on Information Systems

- Information \& Management

- Industrial Management \& Data Systems

- International Journal of Production Economics

- Journal of Enterprise Information Management

- Journal of Information Technology

- Communications of the ACM
- European Journal of Operational Research

- Journal of Information Systems Education

- International Journal of Production Research

- Computers in Industry

In addition to the preceding journals, the following databases were searched: ABI/Inform Global, ACM: Association for Computing Machinery Digital Library, Business Source Premier (EBSCO), Computing (ProQuest), and IEEE Xplore (IEE/IEEE). These databases include hundreds of journals that are categorized as belonging to the business/IT field. The actual selection of the article for inclusion in the compilation was dependent upon the researcher's decision after reading the article title and abstract. If it was determined that the article could possibly contain information that would be indicative of ERP systems, then the article was selected. After reading the selected articles, those that put an enhancement on a selection of CSFs were chosen for in-depth analysis. After a broad search, 524 ERP topic papers were chosen from 113 Journal or conference, among which there are 32 CSF articles. Content analysis was an appropriate analysis approach for the goal of this study: to gain a depth of understanding of the various CSFs which have already been identified by other researchers.

\section{OVERVIEW OF THE ARTICLES}

The criteria for choosing the articles are, first, it should have "ERP" in its title or abstract; second, it should have been published between Jan. 1998 and Nov. 2007; third, it has been published in a journal or a special conference. Therefore, 524 ERP articles from 113 journals or conference were chosen. The criteria for choosing the CSF articles from the above 524 ERP articles are: first, it also should have "CSF" in its title or it is explicitly dealing with "CSF" but doesn't have "CSF" in its title for some reason from the author; second, it is not only focus on one CSF instead of a selection of CSFs. Therefore, $32 \mathrm{CSF}$ articles are chosen from 
524 ERP articles.

A total of 524 articles were considered to contain "ERP" applicable to the research, and within them 32 emphasized "success factors". The first stage of analysis was to compare the publication trend for these 2 types of articles over a period of 10 years, starting at 1998. The numbers of articles published every year for these 2 categories were calculated. Then, the proportions of this year's publication to the whole 10 year period were defined. Finally, the percentages of how many articles of CSF were published within ERP articles in the same year were measured.

We found that 1999 (21.7\%), 2006 (10.6\%) and $2007(12.9 \%)$ were three important years when the percentage of CSF topics were higher among all ERP articles (CSF/ERP \% > 10\%). The number and percentage of ERP and CSF articles published every year were evaluated. For example, in 1999, 23 ERP articles were published. Among them, 5 articles contained reference to CSF of ERP implementation. The 23 ERP articles make up $4.4 \%$ of the total 524 articles, while 5 CSF articles make up $15.6 \%$ of the total 32 articles. The CSF articles occupied $21.7 \%$ of the total ERP articles published in 1999. The second stage is to categorize similar CSF concepts into like categories. After consolidating several categories, 37 possible success factor categories were identified.

There are 37 different CSF factors and the frequencies they have been studied in these $32 \mathrm{CSF}$ articles. The top 10 CSFs from 1998-2007 are: Top

Manager Commitment; Teamwork and Composition; Education and Training; Project Management; Definition of Scope and Goals; Business Process Redesign; Change Management Program and Culture; Champion; Open and Honest Communication; and Choose the Right Vendor Right Package. The third stage is to group CSFs into two time periods to compare them. A 10-years period was divided into 2 equal 5-year periods:
1998-2002, and 2003-2007. Then the CSFs were compared for these 2 groups.

Variances which were larger than $15 \%$ identified the significant difference of CSFs for this 2 year groups, for example, education and training, and technical skill.

The most significant difference between the variances that was larger than $15 \%$ in these 2 groups were analyzed. During 1998-2002, only 42.9\% CSF articles considered education and training for clients as one of the critical factors for ERP implementation. However, during next 5 years, $72.2 \% \mathrm{CSF}$ articles placed a significant on education and training. This factor increased $29.4 \%$ and increased in rank from No. 9 during 1998-2002 to No. 1 during 2003-2007. At the same time, technical skill as a factor dropped from No. 5 to No. 14 , with a decrease of $22.2 \%$.

\section{CONCLUSIONS}

From the content analysis in the previous chapter, there are some significant findings . First, the trend of CSF article published during the last 10 years from figure 1 is not the same as ERP articles. When CSF publication reached its peak time in 1999 and 2006, ERP publication was in relatively low points. During 1999-2000, the number of CSF articles became decrease while ERP articles increase dramatically. Contract to this, from 2004, ERP articles decreased gradually, whereas CSF articles increased again. This may reveal the fact of increased attention on ERP implementation critical success factor by academic world.

Second, the top $10 \mathrm{CSF}$ for 10 year period are: Top Manager Commitment; Teamwork and Composition; Education and Training; Project Management; Definition of Scope and Goals; Business Process Redesign; Change Management Program and Culture; Champion; Open and Honest Communication; and Choose the Right Vendor Right Package. However, we also found that Open 
and Honest Communication and End User Involvement, plays a vital role in ERP implementation.

Third, that researchers paid more attention to human factor than technical factors in ERP implementation. More articles after 2003 put enduser's training or involvement as a CSF instead of technical skills or IT infrastructure. With the development of ERP software, it becomes more mature and needs less attention on technical parts. The success of ERP system implementation draws more on human and business issue than technical issue. Also, the communication among managers, end-users, ERP vendors and project team members becomes more important than before.

After a review of ERP critical success factor literatures, it reveals that many CSF articles are presented based on a review of already published CSF by other authors or limited case studies. As a result, the limitation of this article is the occurrence of duplication in the frequency analysis of the success factors. Also because previous researchers normally focused only on a specific aspect of ERP implementation or a case study, there is little research encompasses all significant CSF considerations. This also leads to the limited sample size of literature on ERP CSF topics.

This research provides a comprehensive compilation of all previously identified ERP implementation success factors. However, several areas of future research seem promising. The first area is to fulfill this research with a larger literature sample size. This could increase the accuracy of the research. More literature review articles are expected as the field becomes more mature. The second area is to assess the difference among CSFs for different cultures or nations, for example, China or Japan vs. United States. The publication articles about CSFs in Chinese ERP implementation is increasing. The third area is to analyze this data in different way, like group them to different time periods. There are may be more significant findings. The last interesting area is to group these 37 CSFs into several groups, such as management or technique. Then compare them in different time periods. The variance could be even bigger.

\section{REFERENCES}

1. Akkermans, H., \& K., V. H. (2002). Vicious and virtuous cycles in ERP implementation: a case study of interrelations between critical success factors. European Journal of Information Systems, 11, 35-46.

2. Al-Mashari, M., Al-Mudimigh, A., \& Zairi, M. (2003). Enterprise resource planning: a taxonomy of critical factors. European Journal of Operational Research, 146, 352-364.

3. Allen, D., Kern, T., \& Havenhand, M. (2002). ERP Critical Success Factors: An Exploration of the Contextual Factors in Public Sector Institutions. Paper presented at the 35th Annual Hawaii International Conference on System Sciences, Hawaii, USA.

4. AMR. (2007). AMR Research Releases Enterprise Applications Market Sizing Reports.

5. Biehl, M. (2007). Success factors for implementing global information systems. Communications of the ACM, 50(1), 53-58.

6. Bingi, P., Sharma, M. K., \& Godla, J. (1999). Critical Issues Affecting an ERP Implementation. Information Systems Management, 16(3), 7-14.

7. Brown, C., Vessey. (1999). Making ERP succeed: turning fear into promise. Paper presented at the International Conference on Information Systems.

8. Chan, C. T. W., \& Sin, H. C. (2007, 23-26 July 2007). Successful Enterprise Resource Planning for Large Chinese Construction Companies. Paper presented at the The 9th IEEE International Conference on ECommerce Technology and The 4th IEEE International Conference on Enterprise Computing, E-Commerce and E- 
Services(CEC-EEE 2007).

9. Cheng, D., Deng, F., \& Li, H. (2006). Critical Factors for Successful Implementation of ERP in China. Paper presented at the IEEE International Conference on e-Business Engineering.

10. de Soysa, S., \& Nanayakkara, J. (2006, 15-17 Dec. 2006). Readiness for ERP Implementation in an Organization: Development of an Assessment Model. Paper presented at the International Conference on Information and Automation.

11. Dowlatshahi, S. (2005). Strategic success factors in enterprise resource-planning design and implementation: a case-study approach. International Journal of Production Research, 43(18), 3745-3771.

12. Duchessi, P., Schaninger, C., Hobbs, D., \& Pentak, L. (1988). Determinants of success in implementing material requirements planning (MRP). Manufacturing and Operations Management, 1, 263-304.

13. Ehie, I. C. a. M., M. (2005). Identifying critical issues in Enterprise Resource Planning (ERP) implementation. Computers in Industry, 56(6), 545-557.

14. García-Sánchez, N., \& Pérez-Bernal, L. E. (2007). Determination of critical success factors in implementing an ERP system: A field study in Mexican enterprises. Information Technology for Development, 13(3), 293-309.

15. Gargeya, V. B., \& Brady, C. (2005). Success and failure factors of adopting SAP in ERP system implementation. Business Process Management Journal, 11(5), 501-516.

16. Gefen, D. (2002). Nurturing clients's trust to encourage engagement success during the customization of ERP systems. Omega, 30(4), 287-299.

17. He, X. J., \& Wu, W. (2006). Factors Affecting Adoption of ERP in China. Paper presented at the International Conference on Computational Intelligence for Modelling Control and Automation,and International
Conference on Intelligent Agents,Web

Technologies and Internet Commerce (CIMCA-IAWTIC'06).

18. Holland, C. R., \& Light, B. (1999). Global enterprise resource planning implementation. Paper presented at the 32nd Annual Hawaii International Conference on System Sciences, Hawaii, USA.

19. Huang, S. M., Chang, I. C., Li, S. H., \& Lin, M. T. (2004). Assessing risk in ERP projects identify and prioritize the factors. Industrial Management \& Data Systems, 104(8), 681688.

20. Hutchins, H. A. (1999). 7 key elements of a successful implementation, and 8 mistakes you will make anyway. Hospital Materiel Management Quarterly, 21(2), 76-82.

21. Jarrar, Y. F., Al-Mudimigh, A., \& Zairi, M. (2000). ERP implementation critical success factors-the role and impact of business process management. Paper presented at the Management of Innovation and Technology (ICMIT).

22. Jing, R., \& Qiu, X. (2007). A Study on Critical Success Factors in ERP Systems Implementation. IEEE.

23. King, S. F., \& Burgess, T. F. (2006). Beyond critical success factors: A dynamic model of enterprise system innovation. International Journal of Information Management, 26(1), 59-69.

24. Krasner, H. (2000). Ensuring e-business success by learning from ERP failures. IT Professional, 2(1), 22-27.

25. Loh, T. C., \& Koh, S. C. L. (2004). Critical elements for a successful enterprise resource planning implementation in small-and medium-sized enterprises. International Journal of Production Research, 42(17), 34333455.

26. Mainwaring, J. (1999). Training - the key to ERP implementation. Manufacturing Computer Solutions, 5, 36-37.

27. Nah, F. F.-H., \& Delgado, S. (2006). Critical 
success factors for enterprise resource planning implementation and upgrade. Journal of Computer Information Systems, 46(5), 99-113.

28. Parr, A., Shanks, G., \& Darke, P. (1999). The Identification of Necessary Factors for Successful Implementation of ERP Systems. Paper presented at the IFIP Working Group 8.2 Conference on New Information Technologies in Organisational Process: Field Studies and Theoretical Reflections on the Future of Work.

29. Peterson, W. J., Gelman, L., \& Cooke, D. P. (2001). ERP Trends.

30. Ribbers, P. M. A., \& Schoo, K.-C. (2002). Designing complex software implementation programs. Paper presented at the 35th Annual Hawaii International Conference on System Sciences, Hawaii, USA.

31. Sarker, S., \& Lee, A. S. (2003). Using a case study to test the role of three key social enablers in ERP implementation. Information \& Management, 40(8), 813-829.

32. Scheer, A.-W., \& Habermann, F. (2000). Making ERP a Success: Using Business Process Models to Achieve Positive Results. Communications of the ACM, 43(4), 57-61.

33. Scott, J. E., \& Vessey, I. (2002). Managing risks in enterprise systems implementations. Communications of the ACM, 45(4), 74-81.

34. Shanks, G., Parr, A., Hu, B., Corbitt, B., Thanasankit, T., \& Seddon, P. B. (2000). Differences in Critical Success Factors in ERP Systems Implementation in Australia and China: A cultural Analysis. Paper presented at the European Conference on Information Systems, Vienna.

35. Skok, W., \& Legge, M. (2001). Evaluating Enterprise Resource Planning (ERP) Systems using an Interpretive Approach. Paper presented at the Special Interest Group on Computer Personnel Research (SIGCPR), San Diego, California.

36. Somers, T., \& Nelson, K. (2001). The Impact of Critical Success Factors across the Stages of
Enterprise Resource Planning Implementations. Paper presented at the 34th Annual Hawaii International Conference on System Sciences, Hawaii, USA.

37. Stefanou, C. J. (1999). Supply Chain Management (SCM) and Organisational Key Factors for Successful Implementation of Enterprise Resource Planning (ERP) Systems. Paper presented at the Americas Conference on Information Systems, Milwaukee, WI, USA.

38. Sumner, M. (1999). Critical Success Factors in Enterprise Wide Information Management Systems projects. Paper presented at the Americas Conference on Information Systems, Milwaukee, WI, USA.

39. Turnipseed, D. L., Burns, O. M., \& Riggs, W. E. (1992). An implementation analysis of MRP systems: a focus on the human variable. Production and Inventory Management, 33, 15.

40. Umble, E. J., Haft, R. R., \& Umble, M. M. (2003). Enterprise resource planning: implementation procedures and critical success factors. European Journal of Operational Research, 146(2), 241-257.

41. Umble, E. J., \& Umble, M. M. (2002). Avoiding ERP Implementation Failure. Industrial Management, 44(1), 25-33.

42. Willis, T. H., \& Willis-Brown, A. H. (2002). Extending the value of ERP. Industrial Management \& Data Systems, 102(1/2), 35-38.

43. Zhang, L. M., Lee, K. O., Zhang, Z., \& Banerjee, P. (2003). Critical Success Factors of Enterprise Resource Planning Systems Implementation Success in China. Paper presented at the 36th Annual Hawaii International Conference on System Sciences, Hawaii, USA. 